\title{
A Strategic Action Plan to Enhance the Accessibility of Healthcare in Rural Areas of Zimbabwe
}

Manenji Mangundu ( $\triangle$ mmangundu@gmail.com )

UNISA https://orcid.org/0000-0003-0737-530X

\section{Lizeths Roets}

University of South Africa

Janse Van Rensburg

University of South Africa

Research article

Keywords: Accessibility, healthcare, health facility, systems model, rural areas

Posted Date: July 20th, 2020

DOl: https://doi.org/10.21203/rs.3.rs-42087/v1

License: (c) (i) This work is licensed under a Creative Commons Attribution 4.0 International License.

Read Full License 


\section{Abstract}

Background: Accessibility to health care in rural areas of Zimbabwe is challenging. Developing a strategic action plan was in essence, a road map leading to a required potential like achieving a goal. Wider consultation with communities, healthcare leaders and policymakers to inform development of strategic action plan, often overlooked has necessitated this research. The aim was to identify strategies and develop a strategic action plan to enhance accessibility to healthcare in rural areas of Zimbabwe through active involvement of key stakeholders like healthcare users, healthcare workers, leaders and legislators.

Methods: A multiple methods approach were used and study was carried out in 4 phases. In Phase 1 (quantitative), data was collected from professional nurses using self-administered questionnaire and health care users using interview questionnaire. Phase 2 (qualitative) collected data through a nominal group with national health directors. A strategic action plan was developed in phase 3 using findings from phase 1 and 2, the Systems Model and a literature control. In phase 4, the strategic action plan was finalised and validated by members of parliamentary portfolio committee on health who were members of parliament of Zimbabwe. Two districts (Masvingo and Chegutu) in two provinces (Masvingo and Mashonaland West) were included in the study, targeting 45 public health facilities in rural areas of Zimbabwe.

Participants included in the study were conveniently sampled professional nurses (90), health care users (445) using the sampled public health facilities (phase 1), conveniently sampled 5 national health coordinators (phase 2) and all-inclusive 5 members of the parliamentary portfolio committee on health (phase 4).

Results: The study contributed to the development and validation of the strategic action plan with 6 strategies. These included improving the health infrastructure, provision of medical drugs, health workers, medical equipment, reviewing the health worker workload and addressing shortages, and improving the capacity of the health care system.

Conclusion: The active participation at all phases by professional nurses, health care users, national health directors and members of parliament contributed to development of a strategic action plan with 6 strategies to enhance accessibility to health care in rural areas of Zimbabwe.

\section{Background}

The goals of every healthcare delivery system in each country in the world is to improved health and wellbeing of the people (Azétsop \& Ochieng, 2015). Citizens in every country, including Zimbabwe, have a right to healthcare. Allocating resources in a fair manner ensures that citizens can access healthcare, essential medical drugs, skilled and adequate healthcare workers, and health facilities (Chandler et al, 2013). However, many rural and remote communities worldwide often experience high levels of inaccessibility of healthcare (Thomas, Wakerman, and Humphreys 2015). Even within the developed world (World Health Organisation (WHO) 2015), equitable and accessible healthcare is difficult to achieve, 
particularly in rural populations where accessibility to quality healthcare can be determined by the socioeconomic status of families (Shah et al 2020). In Zimbabwe, $67.8 \%$ of the population live in rural areas (Zimbabwe National Statistics Agency 2018) and approximately 9 million Zimbabweans (63\%) lack access to healthcare. Eighty-three (83\%) percent of those 9 million people are living in rural areas where professional nurse coverage is merely $38 \%$ of the nursing workforce (Ministry of Health and Child Welfare 2014; Zimbabwe National Statistics Agency 2015).

Some of the health facilities had to close due to this shortage of professional nurses. According to Kevanyet al (2012) the congestion at the few functioning health facilities contribute to long waiting times, delayed diagnosis, and increasing mortality rates that could have been prevented (Nyandoro et al 2016). Alarmingly, it was found that $61 \%$ of mothers in the rural areas fail to take their sick children to the health facilities (Zimbabwe National Statistics Agency. 2015). Forty-five (45\%) percent of pregnant women delivering in the rural areas are assisted by untrained health workers and $32 \%$ deliver at home. The unavailability of midwives may be related to midwives resigning from health facilities in the rural areas to move to urban areas with improved working conditions. Some take on part-time work for an additional income and others emigrate from the country.

According to the WHO (2015), the distance to the nearest health facility should not be more than $5 \mathrm{~km}$ in order to enhance access to healthcare. In Zimbabwe, people in the rural areas walk more than $10 \mathrm{~km}$ and some travel up to $50 \mathrm{~km}$ to the nearest health facility (Loewenson et al 2014).

Buzuzi et al (2016) found that the contribution of household and individual expenditure on health had increased from $45.8 \%$ in 2010 to $67 \%$ in 2015 . This led to limited access to healthcare for those who can afford it, and has exposed the poor to increasingly high costs, resulting in them consulting traditional healthcare services (WHO \& World Bank 2015).

The shortage of medical drugs, vaccines and healthcare workers, as well as transport problems, has affected community outreach programmes like the immunisation of under $5 \mathrm{~s}$. Community outreach programmes have been cancelled (Mhere 2013). In respect of health financing, Zimbabwe's healthcare system has been deeply affected. Every fiscal year, Zimbabwe fails to allocate the minimum $15 \%$ of its annual budget to health as indicated in the Abuja Declaration of 2001, where African leaders had agreed to allocate $15 \%$ of their countries' total fiscal budget to the health sector (Loewenson et al 2014). This might be due to a lack of strategic action planning.

According to Ahmed et al (2014) strategic action plan is, in essence, a road map designed to lead to a required potential, such as the accomplishment of a goal or resolution of a problem. The strategic action plan in this research study also involved a set of established actions or interventions by stakeholders to enhance access to healthcare in the rural areas of Zimbabwe. These stakeholders include members of parliament, national health directors, the Ministry of Health and Child Care, the Ministry of Higher Education and Technology, the Ministry of Labour and Social Welfare and the Ministry of Finance. Strategic action planning assists to identify specific and measurable short-term, mid-term and long-term actions, with appropriate milestones and outcomes that organisations will take to meet each priority 
strategy (Rajan et al 2014). The strategic action plan, as presented in Table 1, illustrates the measures and actions needed to address lack of health infrastructure and shortages of medical drugs, health workers and financial resources, so as to improve the accessibility of healthcare services. 
Table 1

Validated, approved and agreed Strategic Action Plan (actions are included in the text).

$\begin{array}{llll}\begin{array}{l}\text { Systems } \\ \text { Model } \\ \text { Inputs }\end{array} & \begin{array}{l}\text { Theme / } \\ \text { Strategy }\end{array} & \text { Goal } & \text { Outcome } \\ & & & \end{array}$

Physical Resources
1. Develop health infrastructure in the rural areas
- To improve the distribution and the conditions of the health facilities in rural areas of Zimbabwe.
Improved health facility coverage in rural areas of Zimbabwe.

Healthcare users walk less than $5 \mathrm{~km}$ to the health facility.

Increased physical accessibility to health facilities in rural areas.

Improved financial resources for healthcare.

- To improve the necessary infrastructure like water, electricity and communication at the existing health facilities' infrastructure

Improved road access to health facilities, electricity supply, water supply and communication at the health facilities in the rural areas.

Improved motivation of health workers to work at the rural health facilities.

Material 2. Provide - To ensure availability and resources medical drugs at the rural health facilities accessibility to essential medical drugs at the health facilities for the healthcare users and health workers in the rural areas.
To ensure availability and accessibility to essential medical drugs at the health facilities for the healthcare users and health workers in the rural areas.

Improved accessibility to essential medical drugs by the healthcare users in the rural.

Improved availability of medical drugs in rural health facilities.

Improved funding for the procurement of medical drugs. 


\begin{tabular}{|c|c|c|c|}
\hline $\begin{array}{l}\text { Systems } \\
\text { Model } \\
\text { Inputs }\end{array}$ & $\begin{array}{l}\text { Theme / } \\
\text { Strategy }\end{array}$ & Goal & Outcome \\
\hline & & \multirow{3}{*}{$\begin{array}{l}\text { - To ensure good management of } \\
\text { medical drugs at the health facility } \\
\text { level through timely ordering of the } \\
\text { right quantities and type of medical } \\
\text { drugs consumed at the rural health } \\
\text { facilities. }\end{array}$} & $\begin{array}{l}\text { Improved and efficient } \\
\text { medical drug supply } \\
\text { management system. }\end{array}$ \\
\hline & & & $\begin{array}{l}\text { Improved accessibility and } \\
\text { management of medical } \\
\text { drugs at the rural health } \\
\text { facilities. }\end{array}$ \\
\hline & & & $\begin{array}{l}\text { Supported supervisory } \\
\text { visits by specialists at } \\
\text { quarterly ( } 3 \text { months) } \\
\text { intervals. }\end{array}$ \\
\hline \multirow[t]{4}{*}{$\begin{array}{l}\text { Human } \\
\text { resources }\end{array}$} & \multirow{4}{*}{$\begin{array}{l}\text { 3. Develop and } \\
\text { retain human } \\
\text { resources in the } \\
\text { rural health } \\
\text { facilities }\end{array}$} & \multirow{2}{*}{$\begin{array}{l}\text { - To attract and retain health } \\
\text { workers at the rural health facilities } \\
\text { through promotion and payment of } \\
\text { incentives. }\end{array}$} & $\begin{array}{l}\text { Retention of competent and } \\
\text { skilled health workers at the } \\
\text { rural health facilities. }\end{array}$ \\
\hline & & & $\begin{array}{l}\text { Increased job satisfaction } \\
\text { by health workers at the } \\
\text { rural health facilities. }\end{array}$ \\
\hline & & \multirow[t]{2}{*}{$\begin{array}{l}\text { - To build the capacity of health } \\
\text { workers through in-service and on } \\
\text { job mentoring in line with changing } \\
\text { health trends. }\end{array}$} & $\begin{array}{l}\text { Increased motivation by } \\
\text { heath workers to continue } \\
\text { working at the rural health } \\
\text { facilities. }\end{array}$ \\
\hline & & & $\begin{array}{l}\text { Improved retention of } \\
\text { health workers in the rural } \\
\text { health facilities. }\end{array}$ \\
\hline \multirow[t]{3}{*}{$\begin{array}{l}\text { Human } \\
\text { resources }\end{array}$} & \multirow{3}{*}{$\begin{array}{l}\text { 4. Review the } \\
\text { workload of the } \\
\text { health workers } \\
\text { at the health } \\
\text { facilities and } \\
\text { address } \\
\text { shortages }\end{array}$} & $\begin{array}{l}\text { To employ the right number of } \\
\text { health workers based on workload } \\
\text { at the health facility. }\end{array}$ & $\begin{array}{l}\text { The shortage of health } \\
\text { workers is addressed in } \\
\text { rural areas. }\end{array}$ \\
\hline & & $\begin{array}{l}\text { - To ensure an appropriate skill mix } \\
\text { at the health facility level including } \\
\text { estimating workforce requirements }\end{array}$ & $\begin{array}{l}\text { Improved recruitment and } \\
\text { staffing levels at the rural } \\
\text { health facilities. }\end{array}$ \\
\hline & & & $\begin{array}{l}\text { Improved healthcare service } \\
\text { delivery according to the } \\
\text { community needs. }\end{array}$ \\
\hline \multirow[t]{2}{*}{$\begin{array}{l}\text { Material } \\
\text { resources }\end{array}$} & \multirow{2}{*}{$\begin{array}{l}\text { 5. Provide } \\
\text { adequate } \\
\text { material and } \\
\text { minimum } \\
\text { required } \\
\text { medical } \\
\text { equipment in } \\
\text { the health } \\
\text { facilities }\end{array}$} & \multirow[t]{2}{*}{$\begin{array}{l}\text { - To ensure the availability of } \\
\text { adequate, appropriate and well- } \\
\text { maintained medical equipment and } \\
\text { accessories in accordance with } \\
\text { standards at the rural health } \\
\text { facilities. }\end{array}$} & $\begin{array}{l}\text { Improved diagnosis and } \\
\text { healthcare service delivery } \\
\text { by health workers at the } \\
\text { first point of access for } \\
\text { healthcare users. }\end{array}$ \\
\hline & & & $\begin{array}{l}\text { Improved maintenance of } \\
\text { the medical equipment at } \\
\text { the rural health facilities. }\end{array}$ \\
\hline
\end{tabular}




\begin{tabular}{|llll|}
\hline $\begin{array}{l}\text { Systems } \\
\text { Model } \\
\text { Inputs }\end{array}$ & $\begin{array}{l}\text { Theme / } \\
\text { Strategy }\end{array}$ & Goal & Outcome \\
\hline $\begin{array}{l}\text { Managerial } \\
\text { resources }\end{array}$ & $\begin{array}{l}\text { 6. Improve the } \\
\text { capacity of the } \\
\text { healthcare } \\
\text { delivery and } \\
\text { management } \\
\text { systems }\end{array}$ & $\begin{array}{l}\text { - To put in place policies, human } \\
\text { resources, financial resources that } \\
\text { strengthen the healthcare delivery } \\
\text { and management systems } \\
\text { in Zimbabwe. }\end{array}$ & $\begin{array}{l}\text { Resources are used } \\
\text { effectively in the provision } \\
\text { of healthcare services. }\end{array}$ \\
$\begin{array}{lll}\text { Reduction of disease } \\
\text { burden in Zimbabwe. }\end{array}$ \\
\hline
\end{tabular}

The objective of the study was to develop a strategic action plan to enhance access to healthcare in the rural areas of Zimbabwe. The systems model (Fig. 1) was applied to strengthen the effectiveness of healthcare systems (Rajan et al 2014) and all the systems model components were considered during the development of the strategic action plan. The systems model inputs (human, material, physical, financial and managerial) were reviewed and taken into consideration in the findings in Phase 1 (professional nurses and healthcare users), during which the challenges and opportunities with regard to the accessibility of healthcare in rural areas in Zimbabwe were investigated.

The processes in this study, according to the systems model, were the steps taken to bring about the preferred outputs, and involved the strategies as identified by the nominal group participants (national health directors) in Phase 2. These participants (the national health directors), played an essential role in the formulation of the strategic action plan in Phase 3. The important outcome was the strategic action plan that was developed and validated in Phase 4 of the study.

\section{Methods}

A multiple-methods research design was followed during data collection. The study was organised in four phases (Fig. 2). In Phase 1, a quantitative approach was taken to identify the challenges and opportunities inherent in healthcare accessibility in the rural areas of Zimbabwe, and the data was gleaned from a population of 90 professional nurses using a self-administered questionnaire (Annex $A$ ) and 445 healthcare users using a questionnaire (Annex B).

Phase 2 utilised a qualitative method to identify strategies using the nominal group technique (NGT) for the purposes of developing a strategic action plan. The process was guided by the systems model as theoretical framework (Sadeghifar et al 2015). The population in Phase 2 were 15 national health directors of the Ministry of Health and Child Care. Convenient sampling was done, since all willing and available national health directors were invited to participate in the nominal group and ultimately 5 national health directors participated. Data was collected through the nominal group technique. 
The identified strategies were aligned with the systems model inputs (Fig. 1), defining the processes needed to address each strategy and determine outcomes that could be used to develop the strategic action plan. The findings in Phase 1 informed the data collection in Phase 2, which in turn was used to develop the validation form with strategic action plan in Phase 3, which was validated in Phase 4.

The population in Phase 4 were members of parliament of Zimbabwe. The sample was conveniently selected, as all members of the Parliamentary Portfolio Committee on Health (PPCH) who were willing and available were invited and all 5 members of the $\mathrm{PPCH}$ volunteered to participate. The validation process involved 5 steps (Fig. 2). During the 1st step, the draft strategic action plan was presented for review. It was then amended during the 2 nd step, whereupon participants reached consensus on the strategies to be included/excluded in the draft strategic action plan during the 3rd step as illustrated in Annex C. All comments were discussed to ensure that every participant had an equal voice and that the comments were incorporated, allowing the researcher to put in place the strategic action plan for validation in 4th step. In the 5th step, the strategic action plan was shared with all 5 validation participants through emails for approval during a virtual (electronic) meeting, to ensure that all the participants were satisfied and validated the final strategic action plan (Table 1) using the validation form shown in Annex C.

\section{Results}

Six (6) validated and approved strategies were retained (Table 1). The approved and agreed strategies for enhancing the accessibility of healthcare in the rural areas of Zimbabwe were to; (1) develop health infrastructures in the rural areas; (2) provide medical drugs at the rural health facilities; (3) develop and retain human resources (health workers) at the rural health facilities; (4) review the workload of health workers at the health facilities and address shortages; (5) provide adequate material resources at the rural health facilities; and (6) improve the capacity of the healthcare delivery and management systems. The five participants involved in the validation agreed to the final strategic action plan as presented in Table 1.

\section{Discussion}

The strategic action planning was seen as a process of bringing together ideas and resources to strengthen procedures and operations, ensuring that health workers and other stakeholders were focused on common goals, and that a target was set (Sadeghifar 2015). The strategic action plan was the result of a thorough consultative process, as all-important stakeholders - professional nurses and healthcare users (Phase 1), national health directors (Phase 2) and members of parliament (Phase 4) - were actively involved during the development thereof. The process applied by the researcher was in line with accepted strategic action planning procedure. The researcher conducted a literature control for every strategy, which was then thoroughly discussed during validation. The researcher applied the systems model as theoretical framework (Fig. 1), using its components to develop the strategies. The components of the systems model (Rajan 2015) are inputs, processes, outputs and outcomes. Thus, in developing the draft 
strategic action plan, the strategies were analysed and formulated, aligning each strategy with its systems model component. The first strategy in the strategic action plan was to develop health infrastructure (Table 1).

\section{Developing health infrastructure in rural areas}

All healthcare services depend on the existence of a basic health infrastructure and this has been described as critical to the healthcare delivery system (Smith 2015). This was agreed by the participants who identified the strategy and those who validated the strategic action plan. They maintained that the development of health infrastructure is essential and that health facilities should be built within $5 \mathrm{~km}$ walking distance in villages, while existing health facilities should be maintained and rehabilitated. The findings were consistent with a study done in Uganda by the Institute for Health Metrics and Evaluation (Institute for Health Metrics \& Evaluation (IHME) 2014) to evaluate the Ugandan healthcare system, which found that the utilisation of healthcare facilities improved when healthcare users had to travel smaller distances. Health infrastructure provides communities and the nation with the ability to prevent and control disease, promote public health, and prepare and act against disease outbreaks and chronic (ongoing) challenges related to the health of citizens (World Bank 2016). As a result, the members of parliament (i.e. the participants validating the strategic action plan) indicated a willingness to take the responsibility of tabling a motion in parliament to prioritise building health facilities in villages that lack health infrastructure and have a population of 6000 or smaller, and to prioritise the supply of medical drugs at rural health facilities.

\section{Provision of medical drugs to rural health facilities}

According to McKeever et al (2013) medical drugs are necessary to save lives, prevent disease complications, reduce mortality rates and reduce the length of hospital stays (Gray 2014). According to the systems model, medicines are an important part of the material resources input. Challenges related to medicines included inconsistent or short supply at rural health facilities (Mkoka et al 2014). Because of this, action was recommended to establish partnerships with national and international medical drug producers and non-government organisations, and to introduce health levies and local taxes for the procurement of medical drugs in order to facilitate a constant medicine supply pipeline. The findings are similar to a study in Zimbabwe by Jamison et al (2013), who suggested that medical drug supply in the rural health facilities was a challenge that could be addressed through partnerships between the government, private companies, national and international drug producers, and non-government organisations in Zimbabwe. The national health directors suggested the same, after recognising that a lack of sufficient funding for medical drugs from the central government was deterring expectations of improved medical drug availability in rural health facilities. This method has also worked well in some countries like Netherlands, as reported in a study conducted by De Vrueh and Crommelin (2017) on future of pharmaceuticals in public-private partnerships. The major factor contributing to the shortage of 
medical drugs in Zimbabwe was the lack of health workers who had experience in ordering the medicines, and this might have contributed to the national health directors proposing to capacity-build professional nurses on logistics management, focusing on ordering and managing medical drugs at health facilities ${ }^{14}$. This also facilitates the development and retention of human resources.

\section{Development and retention of human resources in rural health facilities}

Human resources form an essential part of the inputs (systems model) required to enhance the accessibility of healthcare (Mkoka et al 2013). Human resources management is the organisational role that regulates issues associated with employees. It includes recruitment, performance management, organisational development, remuneration, employee motivation, and training (Nyandoro et al 2016). The strategy on the development and retention of human resources aimed to address critical shortages of health workers, especially professional nurses, who are key providers of healthcare services in rural areas. As a result, the introduction of incentives like transport and hardship allowances and promoting the career growth of health workers were recommended as actions for retaining the skills in rural health facilities. The study's findings are similar to those of a study in Tanzania by Mkoka et al (2013) who propounded that offering opportunities for career growth (advancement) to health workers to improve their competencies and skills contributed to their retention. When health workers are trained, adequately skilled and retained at their respective health facilities, access to health services will be enhanced. In a study in Zimbabwe by Nyandoro et al (2016), the findings indicated that incentives like rural transport and hardship and housing allowances assisted in addressing staff shortages in rural areas. Of particular importance, as noted by the professional nurses, is the workload versus the number of health workers. Thus, a review of the workload at rural health facilities is crucial.

\section{Reviewing the workload of health workers at health facilities and addressing shortages}

Human resources are inequitably distributed between urban and rural areas and between primary, secondary and tertiary levels of care (Bonfim et al 2016). There are legitimate concerns about balancing the workload and shortages in human resources in health service delivery. Hence, participants agreed to conduct a workload/staff-need assessment in Zimbabwe. Workloads and shortages can be determined by means of the Workload Indicator for Staff Needs (WISN). Okoroafor et al (2019) describes WISN as a method that calculates the number of health workers based on health facility workload. It uses a form of activity analysis (activity standards), together with measures of utilisation and workload to determine staffing requirements. A study conducted in Namibia by McQuide et al (2013), who applied the WISN, found that the country's health facilities had appropriate numbers of professional nurses. However, the nurses were very inequitably distributed between the different types of health facilities, with the total professional nurse workforce in Namibia skewed towards hospitals. This type of inequitable distribution 
could also be the case in Zimbabwe, as some health facilities had four professional nurses while others were manned by only two nurses. In addition to conducting the WISN, it was important to assess the availability of material resources, including medical equipment at the health facilities, as the provision of adequate material resources is essential.

\section{Provision of adequate material resources to the health facilities}

This strategy aimed to improve service delivery to an ever-increasing population with limited or reducing material resources. Hence action was recommended with regard to the procurement and delivery of basic medical equipment (according to the WHO's standard list) to rural health facilities with or without shortages. The findings of this study in respect of material resources agree with the findings of a study done in South America by Bonfim et al (2016). Equipment and medical supplies form an essential part of service delivery at rural health facilities and contribute to improvement in the capacity of the healthcare delivery system.

\section{Improving the capacity of the healthcare delivery and management systems}

The healthcare system functions when financial resources are available to pay salaries, medical drugs, ambulance operations, and other logistics expenditure (Asante et al 2016). The strategy in this study focused on improving the capacity of the healthcare delivery and management systems.

According to researchers in Tanzania, financial resources are required to finance healthcare systems, including healthcare assets and finances which form an integral part of the inputs (systems model) needed to provide access to healthcare (Mkoka et al 2014). The availability of financial resources influences service delivery. In order to strengthen healthcare systems, multi-year funding systems for paying medical drugs, equipment, salaries and allowances are needed (Rajan et al 2014). The financial policies should include funding mechanisms like performance-based health facility grants that ensure the sustainable provision of essential materials and health workers. Strengthening the harmonisation and coordination of all the systems model inputs into all health programmes is essential to improve the capacity of the healthcare delivery system. The members of parliament, together with the national directors, recommended an action to align the health regulations, statutory instruments, and health policies with the new constitution to improve policies that enhance accessibility to healthcare in rural areas (Table 1). The other action they agreed on was to provide training on leadership and financial and resource management to health workers at rural health facilities, in order to translate knowledge into policy and practice, as suggested by research evidence.

\section{Conclusion}


The study contributed to the development of a strategic action plan where all important stakeholders professional nurses, healthcare users, national health directors, and members of parliament of Zimbabwe - were actively involved. Involvement of all of these levels (Ministry of Health and policy makers) to develop and validate the strategic action plan, might enhance its implementation. The accessibility of healthcare in rural areas is vital to healthcare users and health workers, and it is also in the interest of politicians and the country to enhance service delivery and health-related outcomes.

The members of parliament have agreed to conduct an assessment of the conditions of the health facilities' infrastructure, as a starting point, and this should pave the way to enforcing the strategic action plan in line with the infrastructural development policy.

The study led to the development of a strategic action plan in line with the application of the systems model, incorporating the necessary inputs, processes, outputs and outcomes to enhance access to healthcare services in rural areas. The strategic action plan highlighted the need for the mobilisation of financial resources to make medical drugs available, to attract and retain senior managers and professional nurses, to provide the required medical equipment, and to ensure health infrastructure maintenance, as well as to build health facilities that are accessible to the community.

\section{Abbreviations}

IHME: Institute for Health Metrics \& Evaluation

NGT: nominal group technique

PPCH: Parliamentary Portfolio Committee on Health

WHO: World Health Organisation

WISN: Workload Indicator for Staff Needs

\section{Declarations}

\section{Ethics approval and consent to participate}

This study was in partial fulfilment of the requirements of a PhD degree at the University of South Africa and was approved by several ethics committees:

- Research Ethics Committee, Department of Health Studies at the University of South Africa, reference number HSHDC 240/2013

- Medical Research Council of Zimbabwe on 3 July 2014 Approval number: MRCZ/A/1832. 
Written informed consent was obtained from professional nurses and national health directors and was approved by the Medical Research Council of Zimbabwe. Verbal informed consent was obtained from health care users and Medical Research Council of Zimbabwe and Research Ethics Committee approved this. Refer to link http://uir.unisa.ac.za/handle/10500/25086 with details of the Informed Consent forms and Information letters that were shared by participants before the research was conducted.

\section{Consent for publication}

Participants gave consent for publication of this manuscript and there are no direct quotes.

\section{Competing interests}

All the authors declared no competing interests.

\section{Funding}

This research received no specific grant from any funding agency in the public and commercial or not for profit sectors.

\section{Authors' contributions}

MM: researcher, concept and study design; RL and EJR: concept and study design, critical revision and editing; All authors reviewed and approved this manuscript.

\section{Acknowledgement:}

The success of this study would not have been possible without the professional support and guidance from my supervisors, EJR and LR, the participants, respectively national health directors, members of parliamentary portfolio committee for health who made it possible to complete the study. LP, the statistician worked tremendously hard during Phase 1 of the study to ensure consolidation of the information.

\section{Availability of data and materials}

The corresponding author can provide the datasets used and/or analysed based on request.

\section{Questionnaire}

The questionnaires that were developed for this research were uploaded on UNISA Thesis repository and the link is shared as below.

http://uir.unisa.ac.za/handle/10500/25086

\section{References}


1. Ahmed, A, Bwisa, H, Otieno, R \& Karanja, K. Strategic Decision Making: Process, Models, and Theories. Journal of Business Management and Strategy; Vol 5(1). ISSN 2157-6068 (2014).

2. Thomas SL, Wakerman J, and Humphreys Ensuring equity of access to primary health care in rural and remote Australia - what core services should be locally available? International Journal for Equity in Health; 14: 111. PMCID: PMC4625941 (2015)

3. Asante, A, Price, J, Hayen, A, Jan, S \& Wiseman, V. Equity in Healthcare Financing in Low- and MiddleIncome Countries: A Systematic Review of Evidence from Studies Using Benefit and Financing Incidence Analyses. PLoS ONE; 11(4):e0152866. doi:10.1371/journal.pone.0152866. (Accessed April 14, 2017) (2016).

4. Azétsop, J., Ochieng, M. The right to health, health systems development and public health policy challenges in Chad. Philos Ethics Humanit Med 10, 1. https://doi.org/10.1186/s13010-015-0023-z. (2015).

5. Bonfım, D, Laus, AM, Leal, AE, Fugulin, FMT \& Gaidzinski, RR. Application of the Workload Indicators of Staffing Need method to predict nursing human resources at a Family Health Service Rev. LatinoAm. Enfermagem, Vol 24:e2683. (Accessed October 20, 2016). (2016).

6. Buzuzi, S, Chandiwana, B, Munyati, S, Chirwa, Y, Mashange, W, Chandiwana, P, Fustukian, S \& McPake, B. Impact of user fees on the household economy in Zimbabwe. ReBUILD RPC Working Paper.Poverty Reduction Forum Trust (2016).

7. Chandler, IR, Kizito, J, Taaka, L, et al. Aspirations for quality healthcare in Uganda: How do we get there? Human Resources for Health. Uganda. (2013).

8. Okoroafor, S., Ngobua, S., Titus, M. et al. Applying the workload indicators of staffing needs method in determining frontline health workforce staffing for primary level facilities in Rivers state Nigeria. Global Health Research and Policy 4, 35 (2019). https://doi.org/10.1186/s41256-019-0125-z

9. Gray, A. Medicine shortages; unpicking the evidence from a year in South Africa. AMJ; Vol 7(5) p208212. (2014).

10. Institute for Health Metrics \& Evaluation (IHME). Health Service Provision in Uganda: Assessing Facility Capacity, Costs of Care, and Patient Perspectives. Seattle, WA: IHME (2014).

11. Jamison, DT, Summers, LH, Alleyne, G, et al Global health 2035: a world converging within a generation. The Lancet; Vol 382(9908): p1898-955. (2013).

12. Kevany, S, Murima, O, Singh, B et al. Socio-economic status and healthcare utilization in rural Zimbabwe: findings from Project Accept. Institute for Global Health, University of California, San Francisco, CA, USA; Journal of Public Health in Africa, Vol 3:e13. (2012).

13. Loewenson, R, Masotya, M, Mhlanga, G \& Manangazira, P. Assessing Progress towards Equity in Health Zimbabwe. Training and Research Support Centre and Ministry of Health and Child Care, Zimbabwe, in the Regional Network for Equity in Health in East and Southern Africa (EQUINET), Harare Zimbabwe. (2014).

14. McKeever, AE, Bloch, JR \& Bratic, A. Drug Shortages and the Burden of Access to Care: A Critical Issue Affecting Patients with Cancer. Clinical Journal of Oncology Nursing; Vol 17(5). (2013). 
15. McQuide, PA, Kolehmainen-Aitken, R \& Forster, N. Applying the workload indicators of staffing need (WISN) method in Namibia: challenges and implications for human resources for health policy. Human Resources for Health, Vol 11 p64. (2013).

16. Mhere, F. Health insurance determinants in Zimbabwe: Case of Gweru Urban. Journal of Applied Business and Economics. Vol 14(2). (2013).

17. Ministry of Health and Child Welfare. The National Health Strategy for Zimbabwe 2014-2018. Equity and Quality in Health: A People's Right. Harare: Government Printers. (2014).

18. Mkoka, DA, Goicolea, I, Kiwara, A, Mwangu, M \& Hurtig, AK. Availability of drugs and medical supplies for emergency obstetric care: experience of health facility managers in a rural District of Tanzania. BMC Pregnancy and Childbirth, Vol 14 p108. (2014).

19. Nyandoro, ZF, Masanga, GG, Munyoro, G \& Muchopa, P. Retention of Health Workers in Rural Hospitals in Zimbabwe: A Case Study of Makonde District, Mashonaland West Province. International Journal of Research in Business Management, Vol 6 (6). (2016).

20. Rajan, D, Kalambay, H, Mossoko, M, et al. Health service planning contributes to policy dialogue around strengthening district health systems: an example from DR Congo 2008-2013. BMC Health Services Research; Vol 14:522. (2014).

21. Sadeghifar, J, Jafari, M, Tofighi, S, Ravaghi, H \& Maleki, MR. Strategic Planning, Implementation, and Evaluation Processes in Hospital Systems: A survey from Iran. Global Journal of Health Science; Vol 7(2). (2015).

22. Shah et al. Geographic accessibility to primary care providers: Comparing rural and urban areas in Southwestern Ontario. The Canadian Geographer 2020, 64(1): 65-78. (2020).

23. De Vrueh, R.L.A., Crommelin, D.J.A. Reflections on the Future of Pharmaceutical Public-Private Partnerships: From Input to Impact. Pharm Res 34, 1985-1999. https://doi.org/10.1007/s11095017-2192-5. (2017)

24. Smith, D, Roche, E, O'Loughlin, K, et al. Satisfaction with services following voluntary and involuntary admission. Journal of Mental Health; Vol 23 (1p38-45. (2015).

25. WHO \& World Bank. Tracking Universal Health Coverage, First Global Monitoring Report. Geneva, Switzerland. (2015).

26. World Bank. Changing Growth Patterns, Improving health outcomes. Harare, Zimbabwe. (2016).

27. World Health Organisation. Trends in Maternal Mortality: 1990 to 2015. WHO Library Cataloguing-inPublication Data. (2015).

28. Zimbabwe National Statistics Agency. Zimbabwe Demographic Health Survey 2018. Harare: ZIMSTAT. (2018).

29. Zimbabwe National Statistics Agency. Zimbabwe Multiple Indicator Cluster Survey 2014. Final Report. Harare, Zimbabwe. (2015).

\section{Figures}


Input

Physical Resources

- Health facilities

- Pharmacies

- Laboratories

Material Resources

- Medical Drugs

- Equipment and supplies

Human resources

- Professional Nurses

- Midwives

- Physicians

Financial Resources

- Healthcare funding

- Healthcare user fees

Managerial Resources

- Supervision and management support

- Strategies

- Policy

\section{Processes}

Identification of the

strategies that can be employed to develop the strategic action plan
Outputs

The draft

strategic action

plan that

included

planned actions and policy

..

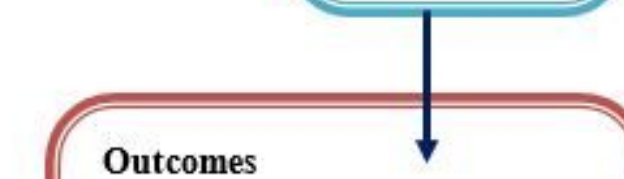

Outcomes

- A validated strategic action plan

Impact

- Enhanced accessibility of healthcare to improve the health and wellbeing of people living in rural areas

\section{Figure 1}

Systems Model (Forester 2009) as applied in the development of a validated strategic action plan to enhance accessibility to healthcare in rural areas 


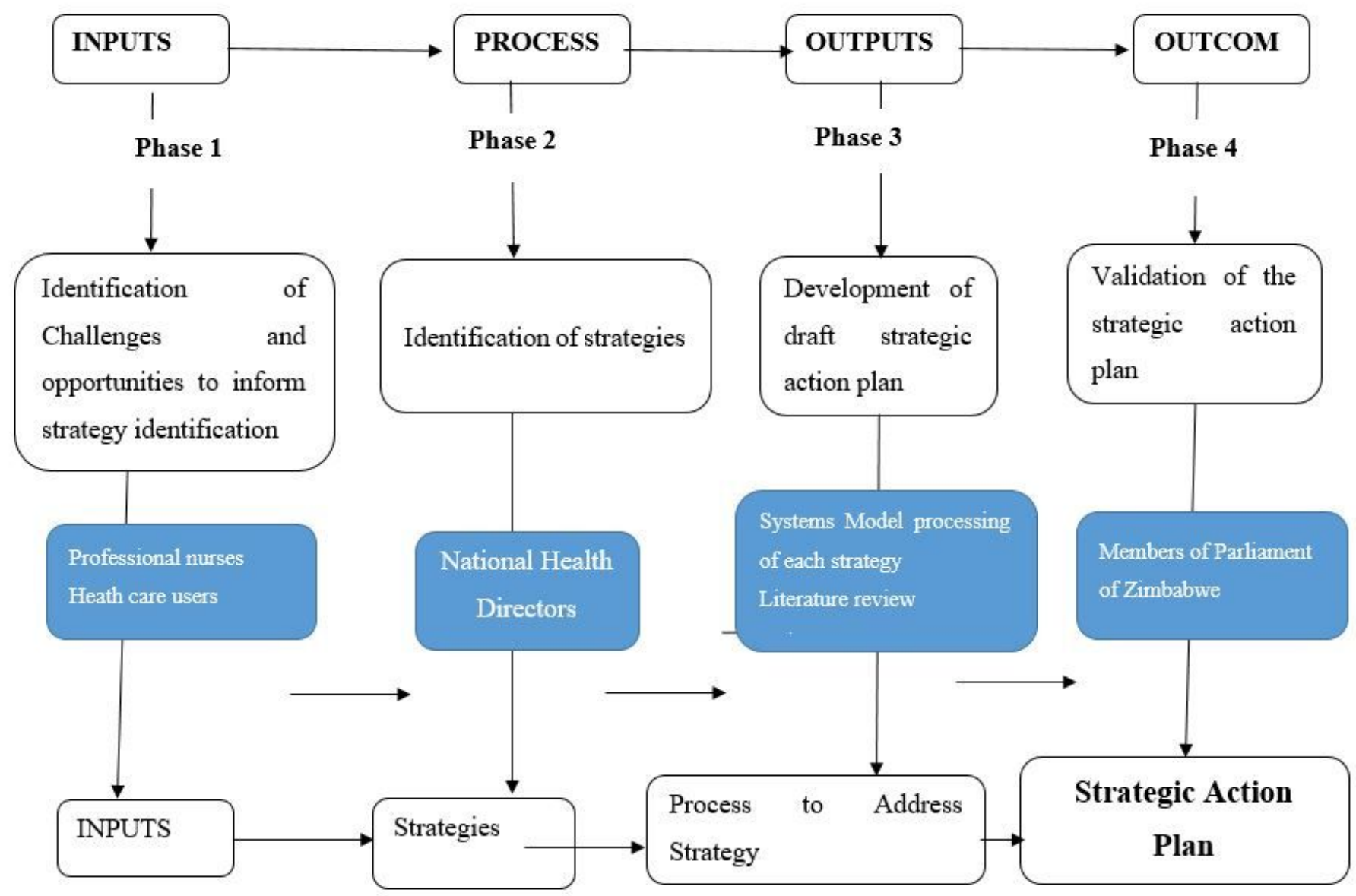

Figure 2

Illustrative diagram of the process of developing the strategic action plan using the Systems Model

\section{Supplementary Files}

This is a list of supplementary files associated with this preprint. Click to download.

- AnnexBQuestionnaireforhealthcareusers.docx

- AnnexAQuestionnairefornurses.docx

- AnnexCStrategyvalidationForm.docx 